\title{
CAPÍTULO 13: REFLEXÕES SOBRE O USO DAS METODOLOGIAS ATIVAS EM AULAS REMOTAS NO ENSINO MÉDIO: UM ESTUDO DE CASO
}

\section{CAPÍTULO 13: REFLEXIONES SOBRE EL USO DE METODOLOGÍAS ACTIVAS EN CLASES REMOTAS EN LA ESCUELA SECUNDARIA: ESTUDIO DE CASO}

\section{CHAPTER 13: REFLECTIONS ON THE USE OF ACTIVE LEARNING IN REMOTE CLASSES IN HIGH SCHOOL: A CASE STUDY}

\author{
Leonardo Rafael Medeiros ${ }^{1}$; Louize Gabriela Silva de Souza ${ }^{2}$; Breno Trajano de Almeida ${ }^{3}$.
}

DOI: https://doi.org/10.31692/978-65-88970-05-8.193-198

\section{INTRODUÇÃO}

Diante do advento da pandemia da COVID-19, instituições do mundo inteiro se encontraram frente a uma nova realidade que inviabiliza a realização das aulas presenciais. Para manter a continuidade dos estudos, governos autorizaram a oferta de aulas remotas emergenciais pelas instituições de ensino, as quais precisaram se adaptar ao novo cenário pandêmico (FAUSTINO; SILVA, 2020).

Muito embora seja uma alternativa emergencial, o ensino remoto impõe uma série de desafios, sobretudo quanto às dificuldades de acesso dos alunos e a falta de formação dos professores em lidar com as novas tecnologias e ferramentas digitais (SILVA et al., 2020). Dessa maneira, o processo de ensino-aprendizagem dos estudantes pode ser comprometido, enquanto o cenário de dificuldades de aprendizagem vivenciadas por alunos, mesmo no formato presencial, pode ser perpetuado.

Nessa perspectiva, as metodologias ativas são uma alternativa promissora a ser adotada no ensino remoto, por proporcionar uma dinamização nas aulas, bem como a possibilidade de o aluno ser protagonista do seu próprio processo de ensino-aprendizagem (DIESEL et al., 2017). Assim, o presente estudo objetiva apresentar contribuições da utilização das metodologias ativas no ensino remoto a partir da análise da aplicação de uma sequência didática em uma turma de Ensino Médio. Este trabalho é um estudo de caso, de cunho qualitativo, e evidencia como as metodologias ativas são alternativas promissoras para se promover um ensino remoto de qualidade, bem como para engajar e motivar os alunos no processo de

\footnotetext{
${ }^{1}$ Mestre em Ecologia e Professor do Ensino Básico, Técnico e Tecnológico do Instituto Federal de Educação, Ciência e Tecnologia do Rio Grande do Norte, Campus Ipanguaçu (IFRN/IP), leonardor.rafael@ ifrn.edu.br

${ }^{2}$ Doutora em Educação e Professora do Ensino Básico, Técnico e Tecnológico do Instituto Federal de Educação, Ciência e Tecnologia do Rio Grande do Norte, Campus Ipanguaçu (IFRN/IP), louize.gabriela@ifrn.edu.br

${ }^{3}$ Mestre em Educação e Professor do Ensino Básico, Técnico e Tecnológico do Instituto Federal de Educação, Ciência e Tecnologia do Rio Grande do Norte, Campus Ipanguaçu (IFRN/IP), breno.almeida@ ifrn.edu.br
} 
aprendizagem.

\section{FUNDAMENTAÇÃO TEÓRICA}

As metodologias ativas vêm sendo amplamente utilizadas nas instituições de ensino brasileiras nas últimas décadas, sobretudo na área da saúde, como forma de contrapor a relação verticalizada entre professor e alunos existente na estrutura educacional historicamente difundida nas escolas (ABREU, 2009).

A principal característica das metodologias ativas é a posição do aluno como o centro do processo de ensino-aprendizagem, levando-o a ter autonomia, pensamento crítico-reflexivo e papel ativo nas aulas. Nesse contexto, o papel do professor deixa de ser o de transmissor de conteúdos para ser um mediador e facilitador da aprendizagem, por meio da criação de ambientes inovadores que problematizam a realidade e fomentam o trabalho em equipe (DIESEL, 2017). Portanto, percebe-se que essas estratégias de ensino entram em consonância com a perspectiva de Freire (2015), o qual defende que as escolas estimulem os educandos a pensarem de forma autônoma e a refletirem sobre suas próprias ideias.

As metodologias ativas oportunizam o desenvolvimento da colaboração entre os alunos (LOVATO et al., 2019), engajamento por meio de atividades lúdicas com a utilização de jogos digitais (SENA et al., 2016), problematização a partir de questões relevantes do cotidiano do estudante, e a adoção de práticas educacionais interdisciplinares contextualizadas e efetivas. Dessa maneira, essas estratégias didáticas permitem o desenvolvimento de diversas competências e habilidades no educando, as quais não seriam possíveis de serem trabalhadas no ensino tradicional a partir de aulas predominantemente monologadas (DIESEL, 2017).

\section{METODOLOGIA}

O presente trabalho é um estudo de caso, de abordagem qualitativa e natureza aplicada (GIL, 2008), desenvolvido na turma de $1^{\circ}$ ano do Curso Técnico Integrado em Agroecología do Instituto Federal de Educação, Ciência e Tecnologia do Rio Grande do Norte, Campus Ipanguaçu (IFRN/IP). O IFRN/IP fica situado no município de Ipanguaçu, no sertão do estado do Rio Grande do Norte, Brasil. O estudo foi desenvolvido nas aulas da disciplina técnica Bioma Caatinga, que registrava 41 matrículas de estudantes com idades entre 14 e 19 anos.

Foi aplicada uma sequência didática, compreendendo três semanas no mês de outubro de 2020, cada uma com atividades assíncronas e um momento síncrono, abordando as seguintes 
temáticas: cadeias e teias alimentares, sucessão ecológica e relações ecológicas. Para cada temática, foi utilizada uma estratégia diferente de metodologia ativa (Quadro 1).

Quadro 1: Distribuição das atividades durante as aulas da sequência didática.

\begin{tabular}{|c|c|c|c|c|c|}
\hline Semana & Assunto & $\begin{array}{c}\text { Metodologia ativa } \\
\text { utilizada }\end{array}$ & $\begin{array}{c}\text { Atividade } \\
\text { assíncrona }\end{array}$ & $\begin{array}{c}\text { Atividade } \\
\text { síncrona }\end{array}$ & $\begin{array}{c}\text { Ferramenta } \\
\text { tecnológica }\end{array}$ \\
\hline 1 & $\begin{array}{c}\text { Cadeias e teias } \\
\text { alimentares }\end{array}$ & $\begin{array}{c}\text { Sala de aula } \\
\text { invertida }\end{array}$ & $\begin{array}{c}\text { Leitura de texto e } \\
\text { realização de quiz }\end{array}$ & $\begin{array}{c}\text { Roda de } \\
\text { conversa sobre } \\
\text { o assunto }\end{array}$ & Socrative \\
\hline 2 & $\begin{array}{c}\text { Sucessão } \\
\text { ecológica }\end{array}$ & Problematização & $\begin{array}{c}\text { Leitura do texto } \\
\text { "Catástrofe e } \\
\text { Renascimento em } \\
\text { Krakatoa" }\end{array}$ & $\begin{array}{c}\text { Discussão em } \\
\text { grupos }\end{array}$ & Jamboard \\
\hline 3 & $\begin{array}{c}\text { Relações } \\
\text { ecológicas }\end{array}$ & Gamificação & $\begin{array}{c}\text { Videoaulas sobre } \\
\text { relações } \\
\text { ecológicas }\end{array}$ & $\begin{array}{c}\text { Aplicação de } \\
\text { quiz gamificado } \\
\text { e jogos }\end{array}$ & $\begin{array}{c}\text { Kahoot, Word } \\
\text { Search Maker e } \\
\text { H5P }\end{array}$ \\
\hline
\end{tabular}

Fonte: Própria (2020).

Cada momento síncrono compreendeu uma aula de 90 minutos, dividida em dois momentos de 45 minutos cada, com uma pausa de 15 minutos. Os encontros síncronos foram realizados via Google Meet, enquanto as atividades assíncronas antecederam os momentos síncronos e foram reunidas no ambiente virtual de aprendizagem do Google Classroom. Além dessas plataformas, em cada semana foram utilizadas outras ferramentas digitais, com o intuito de dinamizar as aulas e possibilitar a aplicação da metodologia ativa pretendida (Quadro 1).

$\mathrm{Na}$ primeira semana, os alunos fizeram leitura de um capítulo do livro didático sobre cadeias e teias alimentares e responderam a um quiz usando o aplicativo Socrative no momento assíncrono, já no momento síncrono foi realizado uma roda de debate a partir das respostas do quiz. Na segunda semana, os alunos leram previamente o texto "Catástrofe e Renascimento em Krakatoa" (AMABIS; MARTHO, 2013), a fim de que, no momento síncrono, a turma fosse dividida em seis grupos para que discutissem entre si três perguntas problematizadoras sobre sucessão ecológica. Cada grupo resumiu suas contribuições em um mural usando a plataforma Jamboard, as quais foram socializadas para todos no final da aula. Já na terceira semana, os alunos assistiram previamente a videoaulas e, assim, foram aplicadas três estratégias gamificadas no momento síncrono sobre relações ecológicas: i) um quiz em tempo real usando o aplicativo Kahoot; ii) um caça-palavras produzido no website Word Search Maker (www.thewordsearch.com/maker); e iii) um jogo da memória virtual, preparado a partir da plataforma H5P (www.h5p.com), com exemplos da Caatinga (Figura 1). 
Figura 1: Jogo da memória virtual sobre relações ecológicas da Caatinga, produzido na plataforma H5P.
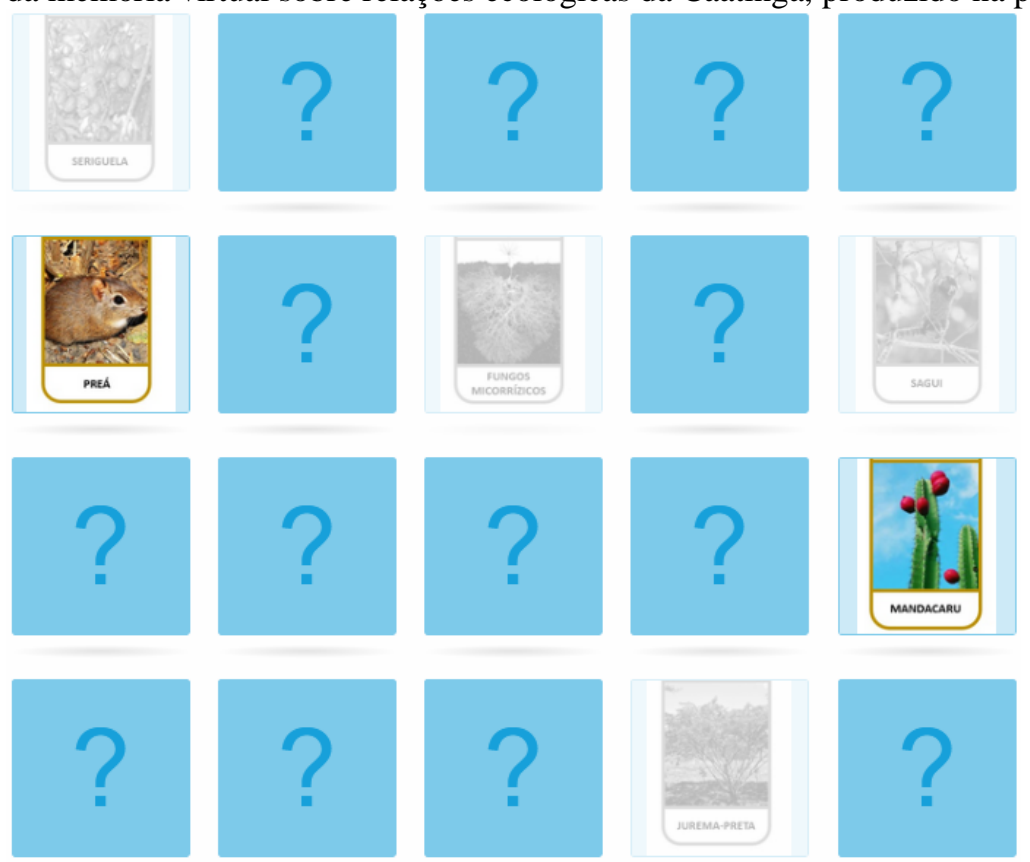

Fonte: Própria (2020).

\section{RESULTADOS E DISCUSSÃO}

A aplicação de diferentes metodologias ativas apresentou um impacto bastante positivo nas aulas, contribuindo significativamente para o aprendizado e satisfação dos alunos. Essas estratégias possibilitaram uma melhor otimização do momento síncrono, bem como um maior engajamento e interação dos alunos com o professor na aula, sendo uma experiência exitosa.

Uma das grandes preocupações de alunos e professores com o ensino remoto é a dificuldade em acompanhar os conteúdos. Todavia, a sala de aula invertida permitiu que o momento síncrono apresentasse maior garantia de aprendizagem, tendo em vista que as discussões aconteceram partindo das próprias dificuldades e dúvidas dos alunos. Esse aspecto da sala de aula invertida é uma das vantagens em relação ao modelo tradicional, pois é possível profundar o assunto, tirar as dúvidas dos alunos, identificar os pontos que mais merecem atenção e ajudar os discentes com suas dificuldades (MARTINS et al., 2019).

O uso da plataforma Jamboard, aliado à problematização, na segunda semana, foi muito bem recebido pelos estudantes, os quais aprovaram o dinamismo e a oportunidade de interação na aula. Essa estratégia possibilitou que alunos dialogassem entre si sobre os conteúdos, permitindo que os próprios colegas explicassem o assunto uns para os outros, participando ativamente do processo de ensino-aprendizagem. Os murais produzidos foram bastante diversos e se apresentaram como uma ótima oportunidade de os alunos desenvolverem a habilidade de síntese, a oralidade e a criatividade (Figura 2). Esses benefícios são comuns nas metodologias 
ativas, as quais, por incentivarem o trabalho em equipe, permitem uma interação constante entre os colegas e o professor, oportunizando momentos de reflexão e colaboratividade (LOVATO et al., 2019), construção de opinião e desenvolvimento das capacidades argumentativas e expressivas (DIESEL, 2017).

O uso do Jamboard foi positivo também uma vez que foi possível evitar que alunos com problemas de conectividade fossem excluídos da aula. Como os alunos foram divididos em grupos, foi possível que um aluno que tivesse melhor aparato tecnológico projetasse o mural do Jamboard em construção, enquanto os outros alunos precisaram utilizar apenas o Google Meet para participar da aula. Muito embora o uso das metodologias ativas no ensino remoto, apesar de relevante, tenha apresentado certas fragilidades para alunos que apresentam problemas de conectividade em alguns estudos (DOSEA et al., 2020), neste trabalho nenhum aluno relatou dificuldade para realizar as atividades propostas. Assim, essa estratégia foi bastante satisfatória e contribuiu para a participação de todos.

Figura 2: Murais produzidos pelos alunos com a utilização da plataforma Jamboard.

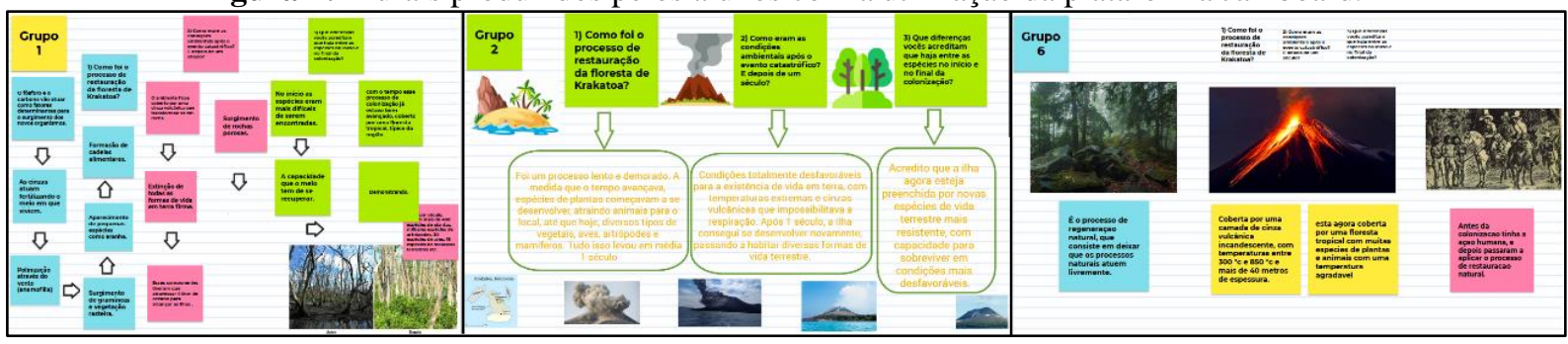

Fonte: Produção dos alunos (2020).

Os diferentes jogos utilizados na terceira semana, além de terem motivado e engajado os estudantes na aula, se apresentaram como uma estratégia divertida e envolvente. Durante todo o momento síncrono, os alunos estavam completamente eufóricos, sob um intenso sentimento de diversão e satisfação. A capacidade de motivar e despertar o interesse dos alunos no processo de aprendizagem é um importante benefício que os jogos virtuais trazem para a área da educação (SENA et al., 2016), auxiliando estudantes a obterem resultados mais satisfatórios (DOMÍNGUEZ et al., 2013). Segundo os alunos, as aulas que compreenderam a sequência didática foram muito prazerosas e contribuíram para que o ensino remoto não fosse tão desestimulador como imaginavam. Esses comentários são relevantes, pois evidenciam que é possível realizar um ensino remoto de qualidade, diversificado e inovador.

\section{CONCLUSÕES}

A partir deste trabalho, percebe-se que o uso das metodologias ativas no ensino remoto 
é possível e elas podem ser implementadas utilizando-se estratégias simples, porém eficientes. Os efeitos positivos observados foram múltiplos e contribuíram sobremaneira para o engajamento dos alunos para a aprendizagem, uma vez que a utilização de metodologias diversificadas e criativas permitiram que o ensino remoto fosse mais divertido e motivador.

\section{REFERÊNCIAS}

ABREU, J. R. P. Contexto atual do ensino médico: Metodologias tradicionais e ativas necessidades pedagógicas dos professores e da estrutura das escolas. Porto Alegre, 2011. 105 p. Dissertação (Ciências da Saúde). UFRGS, 2009.

DIESEL, A.; BALDEZ, A. L. S.; MARTINS, S. N. Os princípios das metodologias ativas de ensino: uma abordagem teórica. Revista Thema, v. 14, n. 1, 2017.

DOMÍNGUEZ, A.; SAENZ-DE-NAVARRETE, J.; DE-MARCOS, L.; FERNÁNDEZ-SANZ, L.; PAGÉS, C.; MARTÍNEZ-HERRÁIZ, J. J. Gamifying learning experiences: practical implications and outcomes. Computers \& Education, v. 63, n. 1, 2013.

DOSEA, G. S.; ROSÁRIO, R. W. S.; SILVA, E. A.; FIRMINO, L. R.; OLIVEIRA, A. M. S. Métodos ativos de aprendizagem no ensino online: a opinião de universitários durante a pandemia de COVID-19. Interfaces Científicas, v. 10, n. 1, 2020.

FAUSTINO, L. S. S.; SILVA, T. F. R. S. Educadores frente à pandemia: dilemas e intervenções alternativas para coordenadores e docentes. BOCA ano II, v. 3, n. 7, 2020.

FREIRE, P. Pedagogia da Autonomia. Saberes necessários à prática educativa. $51^{\mathrm{a}}$ ed. Rio de Janeiro: Paz e terra, 2015.

GIL, A. C. Métodos e técnicas de pesquisa social. $6^{\text {a }}$ ed. São Paulo: Atlas, 2008.

LOVATO, F. L.; MICHELOTTI, A.; SILVA, C. B. LORETTO, E. L. S. Metodologias ativas de aprendizagem: uma breve revisão. Acta Scientiae, v. 20, n. 2., 2018.

MARTINS, E. R.; GOUVEIA, L. M. B.; AFONSECA, U. R.; GERALDES, W. B. Comparação entre o modelo da sala de aula invertida e o modelo tradicional no ensino de matemática na perspectiva dos aprendizes. Experiências em Ensino de Ciências, v. 14, n. 1, 2019.

SENA, S.; SCHMIEGELOW, S. S.; PRADO, G. M. B. C.; SOUSA, R. P. L.; FIALHO, F P. Aprendizagem baseada em jogos digitais: a contribuição dos jogos epistêmicos na geração de novos conhecimentos. Novas Tecnologias na Educação, v. 14, n. 1, 2016.

SILVA, T. S.; ROCHA, L. F.; OLIVEIRA, J. G.; SANTOS, S. L.; SANTOS, L. A.; CRAVEIRO, R. A. O processo de ensino-aprendizagem on-line durante a pandemia de COVID-19: percepção de docentes do ensino médio. In: I CoBICET - Congresso Brasileiro Interdisciplinar em Ciência e Tecnologia, 2020. Evento online. Anais do Congresso Brasileiro Interdisciplinar em Ciência e Tecnologia, 2020. 